\title{
Sobre la noción de responsabilidad política en Hannah Arendt
}

\author{
On the notion of political responsibility in Hannah Arendt
}

\section{Paula Andrea Calderón Melnick*}

\section{RESUMEN}

En el siguiente texto analizamos las reflexiones de Hannah Arendt acerca del ejercicio de la responsabilidad y sus actores asociados. La autora, al intentar rearmar este concepto, señala que la forma de llevar a cabo la responsabilidad es siempre cambiante y gradual, según el nivel de participación que tenga cada sujeto en su comunidad, pudiendo surgir, en primer lugar, una responsabilidad política frente a la colectividad establecida. En segundo término, como forma de oposición al régimen vigente, se puede producir una tensión entre responsabilidad e 'irresponsabilidad', estableciéndose la figura del "desobediente civil". Finalmente, la autora indaga en los momentos en los que existe una imposibilidad de ejercer la responsabilidad, generándose la figura del "objetor de conciencia”, quien se retira de su colectivo de origen enfrentado a una situación de emergencia.

\section{SUMMARY}

In the following text, we analyze Hannah Arendt's reflections on the exercise of responsibility and its associated actors. In an attempt to reassemble this concept, the author points out that how responsibility is carried out is changing and gradual according to the participation level of each subject in their community and a political commitment before the established collectivity may rise. Secondly, as a form of opposition to the current regime, tension may arise between responsibility and 'irresponsibility,'
Palabras clave: responsabilidad, comunidad política, desobediente civil, objetor de conciencia, situación límite.

\section{Keywords:} responsibility, political community, civil disobedience, conscientious objector, borderline situation.

\footnotetext{
* Nacionalidad chilena. Periodista y licenciada en Comunicación Social, Universidad Diego Portales, Chile. Magister en Filosofía, Universidad de Chile. Doctorando en Filosofía, Universidad de Chile. Profesora Adjunta, Centro de Estudios Judaicos, Facultad de Filosofía y Humanidades, Universidad de Chile. Contacto: paulacalderon@uchile.cl
} 
establishing the "civil disobedient" figure. Finally, the author explores the moments in which it is impossible to exercise responsibility, generating the figure of the "conscientious objector," who withdraws from their collective of origin in the face of an emergency. 
En el presente artículo indagaremos en las reflexiones que realiza la pensadora acerca del ejercicio de la responsabilidad en comunidades políticas. Para ello nos introduciremos en los libros de la autora en los que examina este concepto: Responsabilidad y juicio, y Crisis de la República.

Siguiendo estos escritos podemos plantear que la pensadora, al intentar rearmar el concepto de "responsabilidad", señala, en primer lugar, que, frente a la comunidad política de origen, cada sujeto responde de manera distinta al ejercicio de la responsabilidad. Una de las formas de llevarla a cabo será la que Arendt (2018) define como "responsabilidad política" o colectiva, en la que cada individuo debe hacerse cargo del pasado y el presente político de su comunidad, aunque no la haya escogido y no haya intervenido en los hechos allí sucedidos, ejerciendo esta responsabilidad en función de obtener el beneficio de la pertenencia social y política al colectivo: contar con la protección del Estado y la obtención de derechos. Como contraposición, se encuentra la figura del "paria", el "marginado", el "refugiado" y el "apátrida", quienes se convierten en la contracara de los actores que ejercen la responsabilidad colectiva, al no contar con una comunidad admitida como legítima ni aceptada desde su condición. Son individuos que no tienen membresía, al no contar con un Estado que los defienda o con una comunidad política a la que puedan pertenecer, lo que es imprescindible para que surja la responsabilidad colectiva.

En segundo término, como forma de oposición al régimen vigente, se puede producir una tensión entre responsabilidad política e 'irresponsabilidad, al surgir la figura del "desobediente civil". De acuerdo con Arendt (2015), lo que une a estos actores es tener un juicio común contra la política del gobierno, protestando contra leyes, mandatos ejecutivos o políticas que creen injustas, convirtiéndose en un grupo de acción no violento para exigir transformaciones necesarias, organizándose en la esfera pública al percibir que sus demandas no serán escuchadas y que no se producirán modificaciones por parte del gobierno.

Finalmente, la autora explica que la contracara del desobediente civil es el "objetor de conciencia". Mientras que la primera figura actúa políticamente en una comunidad reconocida, el objetor de conciencia debe retirarse de su colectivo, no pudiendo ejercer la responsabilidad 
política hacia su grupo de pertenencia. Estos actores surgen en situaciones de emergencia - lo que la pensadora ejemplificará con el totalitarismo nazi-, decidiendo no participar de los crímenes impulsados por el régimen, aunque sean legales, al guiarse por las proposiciones morales socráticas.

De esta manera, en el presente trabajo analizaremos los distintos tipos de responsabilidad que plantea Arendt, vinculándolos con los actores asociados que devienen del actuar moral. Haremos un recorrido desde la responsabilidad que surge en comunidades políticas democráticas - en las que nacen sujetos responsables políticamente, desobedientes civiles y, su contrapartida, los parias, refugiados y apátridas-, hasta su degradación en los totalitarismos, en los que pueden aparecer individuos que se constituyen en objetores de conciencia para no cometer crímenes en situaciones límite.

\section{Responsabilidad política (colectiva)}

Hannah Arendt señala en su texto Responsabilidad y juicio que, para que surja la responsabilidad política, cada sujeto debe hacerse responsable del grupo al que pertenece, aunque no haya elegido ese colectivo y se realicen allí hechos en los que no ha intervenido. En este sentido, la filósofa alemana plantea que "este tipo de responsabilidad (...) es siempre política, tanto si aparece (...) cuando una comunidad entera asume ser responsable de lo que haya hecho uno de sus miembros, como si a una comunidad se la considera responsable por lo que se ha hecho en su nombre" (153).

De esta cita se desprende que la responsabilidad colectiva es en todos los casos política, ya cuando una comunidad responde obligatoriamente por lo que ha efectuado uno de sus integrantes, como si al colectivo se lo cree comprometido por lo que se ha efectuado en su nombradía. De acuerdo con la autora, en ambos casos existe una responsabilidad política hacia la colectividad de origen, porque la pertenencia al grupo implica "que ningún acto voluntario mío (lo) puede disolver" (Id. 152).

Para comprender lo señalado, podemos recurrir a los planteamientos efectuados por Birulés en la Introducción al libro de Arendt Una revisión de la historia judía y otros ensayos, quien explica que, cuando 
la filósofa alemana se refiere a una comunidad alude a la pertenencia a un grupo que no se ha escogido, en el que no ha intervenido nuestra iniciativa, a una "dotación meramente pasiva del ser del individuo", un "dato incontrovertible" (Arendt 2005 13). Como señala la pensadora española, todo individuo, al nacer, recibe algo de contingente y no elegido, un "presente político“ (Ibíd.), una cierta configuración de mundo que no se vincula con una determinación natural o biológica, ya que toda vida surge en un momento concreto, en el entorno de una comunidad y con unas características particulares.

Birulés sostiene que, para Arendt, el pensar y actuar a partir de la condición dada no se traducirá en que aquello configure una visión del mundo. La autora española indica que, para Arendt, lo que caracteriza a las personas es su capacidad de juzgar "y el primer mandato, al que siempre se mantendrá fiel, es el de 'pensar por sí misma' (Selbstdenken de Lessing)” (Ibíd.). Ello implica, siguiendo a Birulés, que, para Arendt, ejercemos el juicio sobre el fondo de un contexto concreto, de una coyuntura específica; por ello "pensar por sí mismo no es pensar a partir de nada, sino tomar posición, responder de y a lo que nos ha sido dado" (Ibíd.). De esta forma, la pensadora española afirma que, para Arendt, lo que nos ha sido otorgado no determina nuestra visión de mundo y, por ello, frente a lo dado, se toma una posición.

Si nos hacemos eco de las palabras de Birulés, podemos inferir que, frente al colectivo de origen, los sujetos responden de diversas formas en relación con el ejercicio de la responsabilidad. Una de ellas será la que Arendt (2018) denomina como "responsabilidad política", en la que cada individuo se hace cargo del pasado y el presente político de su comunidad, aunque no la haya escogido ni haya intervenido con su actuar. Como contraposición a esta figura, la filósofa alemana hace referencia a los sujetos que abandonan su grupo de origen y, con ello, escapan de la responsabilidad colectiva hacia él. Sin embargo, ello produce que el individuo cambie una comunidad por otra y, con esto, sustituya un tipo de responsabilidad por otra, ya que para la pensadora ningún ser humano puede vivir sin pertenecer a una agrupación.

Para Arendt (2018), no hay norma individual o moral en la vida que pueda evitar nuestra responsabilidad política hacia nuestra comunidad. Esta obligación hacia acciones que no hemos realizado nos vuelve 
representantes de aquellos actos buenos y malos de nuestro colectivo, independiente de que no los hayamos realizado y de los que incluso seamos inocentes. Esta responsabilidad política "es el precio que pagamos porque no vivimos nuestra vida encerrados en nosotros mismos" (Arendt 2018 159), es "la carga" (Id. 154) por poseer la facultad política de actuar y no solo estar encerrados en nuestro pensamiento. De ello se deduce que hacerse responsable políticamente de un colectivo implica asumir la memoria de nuestra comunidad, es decir, tener la capacidad de recordar el pasado y retener el presente de un grupo que ha cometido hechos positivos y negativos, en los cuales no necesariamente ha intervenido nuestro actuar. Sin embargo, si logramos aceptar esta responsabilidad hacia nuestra comunidad, podríamos convertir este resguardo de la memoria en algo positivo, en un impulso hacia la creatividad, con tal de comprender en profundidad lo que ha realizado y efectúa hoy nuestro grupo de pertenencia.

Sin embargo, Arendt (2018 153) indica cómo "el siglo XX ha dado lugar a una categoría de personas que son auténticos marginados, no pertenecientes a ninguna comunidad internacionalmente reconocida, los refugiados y apátridas que, ciertamente, no pueden considerarse políticamente responsables de nada".

De esta cita se deprende que las figuras parias, marginadas, refugiadas y apátridas se convierten en la contracara de los actores que ejercen la responsabilidad colectiva, al no contar con una comunidad admitida como legítima ni aceptada desde su condición. Por ello, de acuerdo con la filósofa alemana, se convierten en los "inocentes absolutos" (Arendt 2018 153), en sujetos libres de culpa al encontrase, por su condición de parias, "fuera de la humanidad como un todo" (Ibíd.). Aquello implica que estos individuos no cuentan con la condición de ser miembros de una entidad y, por ello, no habría nada que exigirles. Son sujetos que no tienen un Estado que los defienda o una comunidad política a la que pertenecer, lo que es imprescindible para que surja la responsabilidad colectiva.

Es en este contexto que Arendt, en su libro Los orígenes del totalitarismo, señala la célebre frase "el derecho a tener derechos" (420), el derecho de todo ser humano a pertenecer a una comunidad políticamente organizada, a ser una persona legal, con derechos inalienables, y pudiendo participar del escenario público. Lo que comple- 
menta Seyla Benhabib en su texto Los derechos de los otros, en el cual plantea la necesidad de que las figuras de "forasteros y extranjeros, inmigrantes y recién venidos, refugiados y asilados" sean incorporadas en "entidades políticas existentes" (13), siendo parte de una justa membresía.

De esta manera, apoyándonos en los planteamientos de Arendt, podemos indicar que contar con una comunidad políticamente reconocida implica para los actores señalados un doble vínculo con la responsabilidad colectiva. Por una parte, se relaciona con una carga, al responsabilizarlos de una colectividad que no han escogido y donde se han efectuado hechos en los cuales no han intervenido. Sin embargo, a su vez, de acuerdo con la pensadora, el vínculo con un grupo reconocido daría a los individuos el beneficio de la pertenencia política además de la protección del Estado, siendo una garantía de su inclusión en la sociedad y de la obtención de derechos. De esta manera, la inclusión en la sociedad, por una parte, y la contracara que son los derechos, tendrían como contrapartida la responsabilidad por lo que no se ha hecho, en un colectivo en el que eventualmente se realizan actos sin intervención del sujeto, y en el que, además, la pertenencia a la comunidad política implicaría "que ningún acto voluntario mío lo puede disolver" (Arendt 2018 152).

\section{Desobediente civil: tensión entre responsabilidad política e 'irresponsabilidad'}

Arendt (2015) explica que los desobedientes civiles son "minorías organizadas" (47) que actúan tras conseguir un acuerdo producido por el consentimiento entre los miembros de uno o varios grupos, lo que justamente valida su opinión. Lo que los une, de acuerdo con la autora, es "la decisión de adoptar una postura contra la política del gobierno" (Ibíd.), protestando contra leyes, mandatos ejecutivos o políticas que creen injustas, convirtiéndose en un grupo de acción no violento en oposición al régimen vigente ${ }^{1}$.

1 Arendt (2015) identificará a los desobedientes civiles con los participantes de las Marchas de la Libertad en Estados Unidos, quienes lucharon por los derechos civiles de los afroamericanos en la década del 60 . 
Asimismo, de acuerdo con los planteamientos de Arendt (2015), estos actores surgen cuando un importante número de ciudadanos se organiza para exigir trasformaciones, al observar que "no funcionan los canales normales de cambio" (59), que sus demandas no serán escuchadas y que no se producirán modificaciones ulteriores por el gobierno. $\mathrm{O}$ al percibir, según la autora, que el régimen "no está a punto de cambiar" (Ibíd.) y permanece en un actuar que produce "graves dudas" sobre su "legalidad y constitucionalidad" (Ibíd.).

Ahora bien, si pensamos, como señalábamos, que la responsabilidad política es cambiante y se presenta en distintos grados, dependiendo de la participación que tenga cada actor en su comunidad de origen, podemos indicar, siguiendo los planteamientos de Arendt (2018), que los desobedientes civiles, enfrentados a su colectividad dada, presentarán una tensión al actuar "irresponsablemente" (73) en ciertos momentos en su grupo de pertenencia con tal de ejercer correctamente su responsabilidad política.

Para comprender qué significa esta tensión, debemos explicar primero la diferencia, que delimita Arendt (2018), entre los conceptos de "consentimiento" (72) hacia una colectividad, versus la "obediencia" (Ibíd.). La obediencia se relaciona con acatar las leyes y a sus representantes, basándose en los argumentos de "que todo cuerpo político está constituido por gobernantes y gobernados, y que los primeros mandan y los segundos obedecen" (Ibíd.) ${ }^{2}$. En tanto que el consentimiento implica un consenso entre las partes, un contrato o acuerdo entre los miembros de uno o varios grupos. Como señalábamos, los desobedientes civiles se caracterizan porque son figuras que adoptan una postura contra la política de gobierno, buscando actuar concertadamente. Por este motivo, de acuerdo con Arendt (2018), el desobediente civil, como su nombre lo indica, no obedecerá "la organización, autoridad o ley que reclama obediencia” (Ibíd.), ya que, al obedecerla, estaría "apoyando" (Ibíd.) aquellas normas que considera ilegales.

Para comprender lo señalado podemos recurrir al texto de Arendt La condición humana, en el que explica que el nacimiento de un ser

2 Planteamientos que, según Arendt (2015), vienen desde Platón y Aristóteles hasta la Ciencias Políticas de nuestros días. 
humano en una colectividad dada no es el comienzo de un "algo", sino que corresponde al origen de un "alguien" (202), que es principiante por sí mismo. Ello implica, según la autora, que con la creación del ser humano se inicia el principio de la libertad, lo que significa que se pueda esperar del hombre lo inesperado, ya que "es capaz de realizar lo que es infinitamente improbable" (Ibíd.). Así, con cada nacimiento ingresa algo absolutamente nuevo al mundo, por que cada ser humano es único e irrepetible, y nadie vivirá lo que él ha vivido. Sin embargo, a su vez, cada individuo deberá asumir la responsabilidad política, la memoria, la carga de aquella comunidad otorgada al nacer, de aquel grupo que ha cometido hechos positivos y negativos, en los cuales seguramente no ha intervenido su actuar.

De esta forma, todos los seres humanos nacemos siendo parte de una comunidad en la que, para sobrevivir, se requiere ser un alguien bienvenido desde lo absolutamente nuevo que trae con su nacimiento, para ejercer el principio de la libertad, la posibilidad de obrar de una u otra manera, o de no obrar, haciéndose responsable de sus actos. En este contexto, Arendt destaca las colectividades en las cuales lo que prima no es el obedecer, sino el "disentimiento" (Arendt 201568), en la posibilidad de no ajustarse al sentir o parecer del grupo de origen, comunidades que permiten el desacuerdo como una "posibilidad legal" (Ibíd.).

De aquello se desprende que la 'irresponsabilidad' del actuar, con la que se vincula la figura del desobediente civil, se debe a que esta figura no estaría contemplada dentro de los marcos legales establecidos por la comunidad, por ello este grupo, al disentir, es eximido de responsabilidad política por su colectivo, porque adopta decisiones importantes sin la debida meditación. Sin embargo, la pensadora señala que el movimiento es justamente el contrario, ya que, cuando existe un gobierno libre, que permite el actuar y el disentimiento de la desobediencia civil, puede ejercer "el asentamiento" (Arendt 2015 68), esto es, puede ampliar los límites de su propio colectivo, al desplegar la responsabilidad política para llevarla a nuevos lugares en las que el grupo pueda expresar juicios ante mandatos ejecutivos, fallas políticas, legales o constitucionales que se desea corregir o trasformar. En otras palabras, si se escucha al desobediente civil se puede generar los cambios necesarios en la comunidad, extendiendo los horizontes de acción y responsabilidad. 


\section{El objetor de conciencia y la imposibilidad de ejercer la responsabilidad política}

Siguiendo los escritos de Arendt, podemos decir que la contracara del desobediente civil es el objetor de conciencia. Mientras la primera figura actúa políticamente en una comunidad reconocida, el objetor de conciencia debe retirarse de su colectivo, no pudiendo ejercer la responsabilidad política. Para la autora, el objetor de conciencia surge sobre todo cuando existe una "situación de emergencia" (Arendt 2015 78), "cuando las cosas se desmoronan" (Arendt 2018 183), lo que ejemplifica con el totalitarismo nazi. En esos momentos límite, los seres humanos no participan de crímenes impulsados por el régimen, aunque sean legales, y no por considerar que "esto no debe hacerse" (Id. 98), lo que para la autora involucraría una obligación, sino por creer que "eso no podemos hacerlo" (Ibíd.)

Como explica Arendt (2018), el objetor de conciencia, enfrentado a su colectivo, no participa de su colectividad de origen, lo que "políticamente (...) es una irresponsabilidad" (98), por tener como "su criterio el yo y no el mundo" (Ibíd.). Aquello lo realizarán estos actores solo en situaciones límite, como en un totalitarismo, una dictadura o en un sistema de opresión, donde los crímenes son promovidos por el régimen de forma legal. En este sentido, como explica Arendt (2018), el objetor de conciencia, al señalar eso no puedo hacerlo, lo que estaría ejerciendo es "la proposición moral (...) no puedo matar a personas inocentes del mismo modo que no puedo decir 'dos y dos son cinco'” (Ibíd.)

Para comprender lo señalado debemos recurrir al texto Georgias (508), en el que Sócrates, referido por Arendt (2018 109), señala que "es mejor sufrir el mal que hacerlo", haciendo referencia a que, si el individuo actúa mal, tendrá que vivir con ese malhechor que es él mismo, y si aquello ocurre y entra en conflicto consigo mismo, estaría forzado a vivir con un enemigo dentro de sí. Sócrates, referido por Arendt (2018), creía en el principio de autocontradicción, destacando a aquellos individuos que temían el desprecio a sí mismos. Y justamente serán ellos, como señala la filósofa alemana, quienes, al vivir "consigo mismos" (Id.97), al tener como su criterio el yo, encontrarán ciertas las proposiciones morales por sí mismas, sobre todo en situaciones de emergencia, por lo que no requerirán ser obligados a actuar moralmente. 
Siguiendo este planteamiento, quienes actúan como objetores de conciencia son aquellos que, enfrentados con una situación de emergencia, son capaces de pensar, es decir, de dialogar consigo mismos, utilizando la capacidad "autodestructiva" (Arendt 2018 166) del pensar, socavando los criterios, conceptos o doctrinas establecidos, con tal de cuestionar "los hábitos y reglas de conducta que son objeto de la moral y la ética" (Id. 174). Ello les permite, por ejemplo, que enfrentados a un régimen como el nazismo, en el que los crímenes son promovidos de forma legal, puedan utilizar, gracias al pensamiento, la proposición moral de Sócrates referida por Arendt: "cometer injusticia es peor que recibirla" (Id. 178). Se trata de aquellas personas que prefieren no participar de la esfera pública de su comunidad de origen, eligiendo ser 'políticamente irresponsables', optando incluso por la muerte de ser necesario, antes que cometer un crimen contra otro ser humano.

En este sentido, la autora indica que el pensamiento, en términos políticos y morales, es un asunto marginal, ya que "beneficiará poco a la sociedad" (Arendt 2018 183) en términos prácticos; sin embargo, enfrentados a un "caso de emergencia (...) su significado político y moral aflora” (Ibíd.). De esta manera, de acuerdo con la pensadora, la figura del objetor de conciencia representa a las personas que, enfrentadas a situaciones límite, cuando la mayoría de los miembros de su colectivo actúan de forma irreflexiva, se niegan a realizar actos delictuales contra otros hombres, y ello "se convierte en una especie de acción (...) lo que es implícitamente político" (Id. 184). Así, en situaciones de emergencia, cuando se pierde la posibilidad de actuar con los miembros de la comunidad de origen, con aquellos individuos que adhieren al régimen totalitario o dictatorial, la forma final para actuar como persona moral y no ser así cómplice del actuar del gobierno, es no actuando en la esfera pública, sino que refugiándose en el pensamiento, que se convierte en una especie de acción política en las últimas instancias de una comunidad en crisis. Como señala Arendt, en el pensar existe la pluralidad, ya que solo se puede reflexionar dividiéndose en dos, aunque se sea uno; esta forma de entender la pluralidad es "como la última traza de compañía" (Id. 120) en las situaciones límite, ya que describimos pluralidad donde no imaginaríamos que existiría.

De esta manera, para Arendt (2018) la moral socrática es políticamente relevante en las situaciones límite, en las que el pensamiento es 
el criterio de la conducta moral y se convierte en una forma de emergencia para no hacer el mal "en tiempos de crisis en que (...) nos hallamos con la espalda contra la pared" (132). Que el yo sea el criterio último de la cuestión moral se da en casos políticamente límite, cuando vemos que la única proposición moral válida es la socrática, que nos dice lo que hay y lo que no hay que hacer; es una forma, de acuerdo con la autora, de estar alertas y decir "detente y piensa" (Id. 119), con tal de interrumpir todo que lo estábamos haciendo para reflexionar desde ese dos-en-uno que somos como seres humanos. Sin embargo, como señalábamos, el pensamiento no debiese primar como conducta moral individual, sino que en momentos que no son de emergencia debiera prevalecer en las comunidades políticas el derecho de todo ser humano a pertenecer a una colectividad políticamente organizada, estando respaldado por una comunidad que acepta el discernimiento como parte de su ser.

Pero, ¿qué pasa con aquellos que, en situaciones de crisis o urgencias, no se detienen y piensan? Tras analizar en sus escritos la figura de Eichmann, en su juicio en Jerusalén, y reflexionar acerca de la noción de "banalidad del mal", Arendt (2018) concluye que existen individuos, como Eichmann, en quienes se produce una "incapacidad de pensar" o una carencia de potencia cerebral, lo que "no es estupidez" (165), ya que se puede encontrar en hombres muy inteligentes, como científicos, investigadores, especialistas, entre otros. Se trata de sujetos que evitan relacionarse consigo mismos, por lo que no se han constituido en personas morales, ya que no participan del proceso del pensar.

Para Arendt, el mayor problema del comportamiento de estos sujetos en situaciones límite, como Eichmann, es que, al no pensar, al no reconocer que son seres dialogantes compuestos por un-dos-enuno, en pluralidad, terminan adhiriendo a cualquiera de las normas o reglas de conductas vigentes en la comunidad, sin un examen crítico de lo que sucede. Por lo cual, en situaciones de emergencia, no toman decisiones y es más fácil para ellos caer en las nuevas reglas impuestas por el régimen ${ }^{3}$.

3 Arendt (2018) ejemplifica lo anterior con el totalitarismo nazi: "Cuánto más firmemente los hombres se aferren al viejo código, tanto más ansiosos estarán por asimilar el nuevo; la facilidad con la que, en determinadas circunstancias, tales inversiones pueden tener lugar sugiere realmente que, cuando ocurren, todo el mundo está dormido. Nues- 
Lo que implica, siguiendo a Arendt (2018), que aquellos que actuaron de acuerdo con la moral que el nuevo régimen imponía, aunque supusiese cometer crímenes contra otros ciudadanos, presentaron una incapacidad para pensar, al cumplir normas, leyes o políticas que implicaban cometer trasgresiones contra otros; ya que es justamente a través del pensar, sobre todo en situaciones de emergencia, que el ser humano debiese estar siempre reflexionando y repensando las normas, sin llegar y cumplirlas sin reflexión.

De ello se deduce, siguiendo a Arendt (2018), que existe una "conexión entre pensar y recordar" (110). Recordar, de acuerdo con la autora, se relaciona con el remordimiento de olvidar lo que se ha realizado, en 'volver a ello', tal como lo indica el verbo en hebreo shuv" (110); por ello se recuerda lo que se ha pensado a fondo, mediante al diálogo con uno mismo. Pensar y recordar son formas de echar raíces, de ocupar nuestro propio lugar en el mundo. Sin embargo, aquellos que presentan 'una incapacidad de pensar' abandonan también el recordar, el remordimiento, el volver sobre lo que se ha realizado, el echar raíces, por lo que estarían dispuestos a cumplir o realizar cualquier cosa que se les ponga por delante, sin reflexionar acerca de ello. Arendt analiza así la situación límite del totalitarismo nazi, para reflexionar en el extremo en el que se podría encontrar la figura del objetor de conciencia y su facultad de detenerse y pensar.

Sin embargo, quienes piensan y recuerdan, indica Arendt (2018), se convierten en "personas" (113), en personalidades morales o en "hombres buenos" (Arendt 2015 52), quienes, al tener enraizado el ser en sus pensamientos y recuerdos, son conocedores de que deben vivir consigo mismos y, por ello, con las proposiciones morales, por lo que tienen límites autoimpuestos de lo que pueden y no pueden hacer, sobre todo en situaciones límite, que es cuando se prueba nuestro actuar éticomoral, en las crisis o urgencias de nuestra comunidad.

De esta manera, podemos indicar que la figura del objetor de conciencia se transforma en persona u hombre bueno al recordar y pensar, y, por ello, al actuar moralmente en situaciones límites, siendo conocedor de que debe vivir consigo mismo y que el costo de no actuar en 
función del régimen o su comunidad implica una retirada de la esfera pública, muchas veces de forma individual, teniendo solo el pensamiento y el recuerdo como compañía. A este modo de existir, "al modo de existencia presente en ese diálogo silencioso conmigo mismo lo llamaré ahora solitud" (Arendt 2018c 113).

La solitud implica, siguiendo a la pensadora que, aunque esté solo estoy con alguien, con ese dos-en-uno que cada uno de nosotros es, por ello, aunque esté en soledad, siempre estaré acompañado por el diálogo que se produce en mi interior. Ello cobra importancia en situaciones límite, en las cuales la preocupación por el pensamiento como criterio último de la conducta moral se da en soledad y su validez se sustenta en la proposición moral socrática señalada anteriormente. Ahora bien, la autora explica que la solitud puede ser interrumpida por otro individuo y, cuando aquello sucede, la persona deja el estado de pensar y empieza "a hablar de forma dialogal (...) como si yo me dirigiera a otro yo. $\mathrm{Y}$ este otro yo, allos autós, fue correctamente definido por Aristóteles como el amigo" (Arendt 2018 113).

Para comprender lo señalado nos debemos remontar a los griegos, para quienes la esencia de la amistad consistía en el discurso; se sostenía que solo el intercambio de ideas unía a los ciudadanos en la polis. En el discurso, la importancia política y su peculiar humanidad quedaban de manifiesto. En este sentido, Arendt indica que la conversación relaciona a los individuos con el mundo común, el que permanece inhumano hasta el momento en que los seres humanos hablan de él. En este contexto destaca la figura de Lessing, quien realiza el discernimiento teórico de que no puede haber una sola verdad dentro del mundo humano, produciéndose así un interminable discurso entre los hombres, el que jamás cesará mientras los seres humanos sigan existiendo (Calderón 2013).

Como afirmábamos, para que exista el pensamiento y el diálogo entre buenos hombres se requiere que las personas sean amigas, ya que la validez de las proposiciones socráticas depende de quienes las expresan y de la clase de ser humano a quien se dirige. Así, la figura de la amistad surge cuando una persona entra en diálogo con otra, y dialoga acerca de los mismos contenidos en los que uno y otro se habían interesado mientras estaban en solitud o en el proceso del pensar. Entonces, en la amistad, cada persona se dirige a un otro yo, lo que 
cobra especial importancia en las situaciones de emergencia, donde la mayor parte de los individuos de la comunidad de origen adopta las leyes y normas del nuevo régimen; mientras que solo unos pocos, los objetores de conciencia, las personas o los buenos hombres, actúan moralmente, lo que los convierte en miembros de una especie de resistencia última frente al actuar de gobiernos que promueven leyes o políticas que legalizan el crimen dentro de su marco institucional.

En este contexto, Arendt (2005b) indica que el objetor de conciencia presenta una capacidad de compresión de su situación actual, del momento de crisis en el que se encuentra su comunidad, lo que le permite "estar en casa en el mundo" (371), es decir, poder situarse existencialmente y aceptar la realidad que lo rodea, incluso en situaciones de emergencia. Proceso de comprensión que no es lineal, sino que es siempre dinámico, cambiante y que no genera resultados concluyentes, pero que finalmente "es el modo específicamente humano de estar vivo" (Id.372), desde el nacimiento hasta la muerte.

\section{Reflexiones finales}

Si observamos los planteamientos de Arendt en relación con la noción de responsabilidad, podemos plantear que, en las obras de la autora analizadas, se encuentra, de forma transversal, la pregunta por cómo se ejerce la responsabilidad política según el grado de participación que tenga cada individuo en su comunidad de origen. Se ha podido observar cómo surgen distintos actores, los que asumen roles diferenciados dependiendo de los contextos concretos en los que se efectúa el actuar moral.

En este sentido, podemos decir, en primer lugar, que ejercemos la responsabilidad política cuando asumimos la pertenencia a nuestra comunidad de origen, aunque no la hayamos escogido y se realicen en ella hechos donde no ha intervenido nuestro actuar. De esta manera, continuando con la lectura de Arendt, podemos apreciar cómo la pertenencia a un grupo organizado y la consecutiva responsabilidad política hacia este presenta aspectos positivos y negativos en relación con nuestra pertenencia a una colectividad dada. En este sentido, ejercer la responsabilidad política o colectiva implicaría hacernos cargo del pasado y del presente político de nuestra comunidad de origen. Aquello lo realizamos, ya que el ingreso a una comunidad reconocida 
nos otorga el beneficio de la pertenencia política hacia un colectivo, además de la protección del Estado, siendo una garantía de nuestra inclusión en la sociedad y la obtención de derechos. Así, la inclusión en la sociedad, por una parte, y la contracara que son los derechos, tendrían como contrapartida la responsabilidad política por lo que no se ha hecho, en un colectivo donde se han realizado acciones en las que no hemos intervenido.

Ahora bien, la pensadora explica que la contracara de la persona responsable por su grupo de pertenencia son los parias, marginados, refugiados y apátridas. Estos actores no son considerados políticamente como responsables, porque no cuentan con una comunidad admitida como legítima ni aceptada - al no tener membresía-, un Estado que los defienda o una comunidad política a la que pertenecer.

En segundo lugar, Arendt identifica la figura del desobediente civil quien, enfrentado a su comunidad de origen, presenta una tensión entre un actuar 'irresponsable' y responsable políticamente. Estos actores se caracterizan por adoptar una postura contra la política del gobierno, buscando actuar concertadamente al tener un juicio común, protestando contra leyes, mandatos o políticas que creen injustos, convirtiéndose en un grupo de acción no violento de oposición. De acuerdo con la pensadora, contar con la figura del desobediente civil permite que en las comunidades haya actores que se atrevan a discernir, a señalar las diferencias y contradicciones al interior de su comunidad, permitiendo que se genere el asentamiento, el ampliar los límites de su propio colectivo y desplegar la responsabilidad política hacia nuevos lugares en los que el grupo pueda establecerse.

La contracara del desobediente civil es el objetor de conciencia. Mientras el primero puede ejercer la responsabilidad política en su comunidad de origen, el objetor de conciencia decide retirarse de su colectivo de origen, no pudiendo ejercer la responsabilidad política en momentos de urgencia, como por ejemplo un totalitarismo, una dictadura o un sistema de opresión, en el que los crímenes son promovidos por el régimen de forma legal y las normas dejan de ser válidas. Los objetores de conciencia son aquellos seres humanos que, enfrentados a una situación límite, son capaces de dialogar consigo mismos, utilizando el pensamiento, y cuestionar los hábitos y reglas de conducta que son objeto de la moral y la ética. Gracias a la reflexión recurren a 
la proposición moral socrática, lo que es políticamente relevante solo en momentos de emergencia, cuando el pensamiento es el criterio de la conducta moral y se convierte en una forma para no hacer el mal en tiempos de crisis. Para Arendt, la pluralidad del pensamiento se podría entender como la última traza de compañía solo en esos momentos, ya que descubre pluralidad al interior de nosotros mismos.

Tras realizar este recorrido por la noción de "responsabilidad", podemos decir que, para Arendt, el ejercicio de la acción moral cambia gradualmente según el contexto político en el que se sitúe el individuo. De esta manera, se puede producir un salto desde la figura que es responsable políticamente en su comunidad de origen hacia la figura de la desobediencia civil, generándose una tensión entre responsabilidad e irresponsabilidad, con el objetivo de protestar contra leyes o acuerdos impulsados por el gobierno. Aquello puede derivar a su vez en la figura del objetor de conciencia, si surgen crímenes impulsados de forma legal por el régimen vigente.

Estos actores no nacen de un momento a otro, sino que la conciencia de estas figuras se elabora gradualmente de acuerdo con el actuar moral de cada sujeto en su comunidad. De esta forma, podemos proyectar que un individuo que actúa responsablemente frente a su comunidad de origen, en democracia - aunque no haya escogido ese colectivo o se realicen en él acciones donde no ha intervenido su actuar-, y se preocupa por ampliar la responsabilidad política hacia aquellas personas que no tienen derechos, como parias, refugiados o apátridas, probablemente se transformará en desobediente civil apenas observe que determinado régimen o gobierno no está cumpliendo con las normas, leyes o decretos políticos que debiese efectuar o que cree injustos. Siguiendo a Arendt, estos sujetos, al intentar comprender su realidad y estar atentos al pasado y presente de su grupo de origen, son conscientes de la importancia de pertenecer a un colectivo que otorgue derechos a todos sus integrantes, pudiendo detectar las anomalías que surjan en su comunidad y actuar con discernimiento, invitando a corregir aquellos mandatos, fallas legales, ejecutivos o constitucionales que se desea transformar.

Asimismo, podemos proyectar que, si un individuo fue responsable políticamente en democracia, enfrentado a una situación de emergencia como un totalitarismo, en el cual el régimen validó crímenes como 
parte de su actuar, probablemente decidirá actuar como un objetor de conciencia, retirándose de la esfera pública con tal de llevar a cabo la proposición moral socrática y actuar como una persona moral en momentos de crisis. Ahora bien, esta secuencia se podrá probar solo en instantes límite, en los que realmente se observa el actuar de los individuos; una acción no lineal, siempre cambiante en distintas direcciones y que se presenta de forma gradual. Por ello, solo sabremos como actúa cada sujeto cuando esté enfrentado a un momento de urgencia, y consigo mismo deberá decidir qué tipo de ser humano quiere ser: un ser pensante capaz de encontrarse con 'otros yo' tras la solitud, llevando una acción anclada en la comunicación, la solidaridad y la valentía; o, por el contrario, un individuo incapaz de reflexionar, sin arraigo, memoria, creatividad ni comprensión.

\section{Bibliografía}

Arendt, H. Responsabilidad y juicio. (7a ed.) Barcelona: Paidós, 2008.

Arendt, H. Crisis de la república. Madrid: Trotta, 2015.

Arendt, H. Los orígenes del totalitarismo (4a Ed.). Madrid: Alianza, 2010a.

Arendt, H. La condición humana (6 ${ }^{\mathrm{a}}$ Ed.). Buenos Aires: Paidós, 2010b.

Arendt, H. Hombres en tiempos de oscuridad (2a Ed.). Barcelona: Gedisa, 2008.

Arendt, H. Una revisión de la historia judía y otros ensayos. Introducción de Fina Birulés. Buenos Aires: Paidós, 2005a.

Arendt, H. Ensayos de Comprensión. 1930-1954. Madrid: Caparrós editores, 2005b.

Arendt, H. Conferencias sobre la filosofía politica de Kant. Barcelona: Paidós, 2003.

Arendt, H. De la historia a la acción. Barcelona: Paidós, 1995.

Benhabib. S. Los derechos de los otros. Barcelona: Gedisa, 2005.

Calderón, P. Hannah Arendt y la condición judía. Paria y advenedizo, dos actitudes posibles para enfrentar la judeidad (Tesis para optar al grado de Magister). Universidad de Chile, 2013.

Kohn, J. y Feldman, R. (Ed.). Hannah Arendt. Escritos judíos. Madrid: Paidós, 2009. 